\title{
A study of the effect of vitamin $D$ in rats maintained on diets with different mineral content but with the same low ratio of calcium to phosphorus
}

\author{
By R. B. HARRAND AND R. L. HARTLES \\ Department of Dental Sciences, School of Dental Surgery, \\ University of Liverpool
}

(Received 20 March I967-Accepted I4 August I967)

\begin{abstract}
I. Eight groups of weanling rats were maintained for 60 days on diets containing calcium and phosphorus in the ratio $0^{-} \mathrm{I}$ at four different levels of mineral, namely $0.08,0.12,0.23$ and $0.32 \% \mathrm{Ca}$, and in the presence and absence of added ergocalciferol.

2. Provision of vitamin $D$ increased final body-weight, whereas at the highest mineral intake body-weight was reduced.

3. At each level of dietary mineral the serum $\mathrm{Ca}$ concentration was raised by vitamin $\mathrm{D}$, whilst the serum $P$ concentration was lowered except when the mineral intake was lowest.

4. With increasing mineral intake the serum $\mathrm{Ca}$ increased until at the highest intake it declined. Serum $P$ was increased only at the highest mineral intake.

5. Measurements were made of bone weights, ash content and volume. Provision of vitamin $\mathrm{D}$ increased the fresh weight of bone at all levels of dietary mineral, and the dry weight and ash content were increased except at the lowest level of mineral intake. In general, the higher the dietary mineral the greater was the bone weight and its ash content.

6. The presence of vitamin D resulted in an increase in tooth mass and ash content at each level of mineral intake. Tooth mass and ash increased with increasing dietary mineral except at the highest level when there was a decline.

7. At the lower levels of mineral intake the ratio of tooth mass to bone mass was greater than at the higher levels of intake.

8. Histological examination of the bones revealed no increase in the width of the epiphyseal cartilage in any group. In the group with the lowest levels of $\mathrm{Ca}$ and $\mathrm{P}$ without vitamin $\mathrm{D}$ $(0.08 \% \mathrm{Ca}, 0.8 \% \mathrm{P})$ the shafts of the femurs appeared thinner and porotic, and the trabeculae were thin; in the group fed the same diets supplemented with vitamin $\mathbf{D}$ the shafts were even thinner but less porotic; in all other groups the histological appearance of the bone was within normal limits.
\end{abstract}

9. Changes in the appearance of the dentine were demonstrated in all groups.

We have already reported on the effect of vitamin $\mathrm{D}$ on the serum $\mathrm{Ca}$ and $\mathrm{P}$, and the bones and teeth of young rats that received diets containing $\mathrm{Ca}$ and $\mathrm{P}$ at two suboptimal levels and in the ratio of $x \cdot 0$ (Harrand, Green \& Hartles, 1966).

In the study now reported weanling rats were maintained on diets with or without added vitamin $\mathrm{D}$ and at four different levels of dietary minerals, but with a constant $\mathrm{Ca}$ to $\mathrm{P}$ ratio of $\circ \cdot \mathrm{x}$. The experiments were designed to gain further information concerning the important relationships existing between the levels of dietary $\mathrm{Ca}, \mathrm{P}$ and vitamin $\mathrm{D}$, and the mineralization of bones and teeth. In particular it was hoped to determine any differences, between the bone and tooth, in response to the same nutritional circumstances. The four levels of dietary $\mathrm{Ca}$ were $0.08,0.12,0.23$ and $0.32 \%$. The highest level of $\mathrm{Ca}$ was below that usually considered desirable for the rat, whereas even the lowest $P$ content $(0.8 \%)$ was higher than the generally accepted optimal. There was therefore a great disturbance of mineral intake in both absolute 
and relative terms. The effects of these treatments, together with the effect of added vitamin $\mathrm{D}$, were assessed by measuring final body-weight, serum $\mathrm{Ca}$ and $\mathrm{P}$, weight, volume, length and ash content of the bones, and weight and ash content of the incisor teeth.

\section{EXPERIMENTAL}

Animals. Eighty black and white weanling rats (21-24 days old) from our own colony were distributed in ten blocks of eight animals according to weight and sex. There were five blocks of males and five of females, the weights of the animals within each block being as similar as possible.

Treatments. One animal from each block was assigned at random to each of eight treatment groups designated I, ID, 2, 2D, 3, 3D, 4 and $4 \mathrm{D}$. Each group consisted of five male and five female rats.

Diets. The basal diet contained sucrose ( $1340 \mathrm{~g})$, egg albumen (400 g) and groundnut oil (100 g). This mixture contained $0.026 \% \mathrm{Ca}$ and $0.06 \% \mathrm{P}$. The $\mathrm{Ca}$ and $\mathrm{P}$ contents of the diets were adjusted by the addition of appropriate mixtures of AR grade salts.

In all diets, to each $1840 \mathrm{~g}$ of basal diet were added $80 \mathrm{~g}$ of salt mixture containing neither Ca nor P (Harrand et al. 1 966 ), $40 \mathrm{ml}$ of water-soluble vitamin solution (Hartles \& Leaver, 1961) and $40 \mathrm{mg}$ biotin.

The following salts were added to the diets for the several groups:

$\begin{array}{ccc} & \mathrm{CaCO}_{3} & \mathrm{KH}_{2} \mathrm{PO}_{4} \\ \text { Groups } & (\mathrm{g}) & (\mathrm{g}) \\ \mathrm{I} \text { and } \mathrm{ID} & 2 \cdot 75 & 65 \cdot 0 \\ 2 \text { and } 2 \mathrm{D} & 4 \cdot 75 & 100 \cdot 0 \\ 3 \text { and 3D } & 10 \cdot 75 & 206 \cdot 0 \\ 4 \text { and 4D } & 16 \cdot 75 & 311 \cdot 0\end{array}$

In groups $1-4$, the groundnut oil contained vitamins $A, E$ and $K$; in groups $I D$, $2 \mathrm{D},{ }_{3} \mathrm{D},{ }_{4} \mathrm{D}$, the oil also contained ergocalciferol (Hartles \& Leaver, I96I).

The main features of the eight dietary treatments were:

$\begin{array}{cccc}\text { Group } & \begin{array}{c}\mathrm{Ca} \\ (\%)\end{array} & \begin{array}{c}\mathrm{P} \\ (\%)\end{array} & \begin{array}{c}\text { Ergocalciferol } \\ (\mu \mathrm{gg} / \mathrm{kg} \\ \text { diet })\end{array} \\ \text { I } & 0.08 & 0.8 \mathrm{I} & \text { None } \\ \text { ID } & 0.08 & 0.8 \mathrm{I} & 200 \\ \text { 2 } & 0.12 & 1.18 & \text { None } \\ \text { 2D } & 0.12 & 1.18 & 198 \\ \text { 3 } & 0.23 & 2.32 & \text { None } \\ \text { 3D } & 0.23 & 2.32 & \text { I87 } \\ 4 & 0.32 & 3.21 & \text { None } \\ 4 \mathrm{D} & 0.32 & 3.21 & 178\end{array}$

With the increasing amount of minerals in the diet the proportion of other components decreased slightly; this is exemplified by the figures for ergocalciferol.

Husbandry. The rats were housed in screen-bottomed cages without access to direct sunlight at a temperature of $21-22^{\circ}$. They were given the diets and deionized water in unrestricted amounts and were weighed weekly and at the end of the experiment. The 
experiment was divided into two parts; in the first, forty-eight animals were housed three of one sex to a cage; in the second, thirty-two animals were housed two of one sex to a cage.

Duration of experiment. The animals were maintained on their diets for 60 days, anaesthetized by diethyl ether inhalation and killed by decapitation to enable blood to be collected.

Serum analysis. Terminal serum $\mathrm{Ca}$ and inorganic $\mathrm{P}$ were determined as described by Hartles, Leaver \& Triffitt (1963).

Bone and incisor tooth measurements. The humeri from each animal were dissected, stripped of soft tissue and weighed. The displacement volume was determined by weighing in air and in water. The maximum length of the humerus was measured with calipers. The bones were then extracted with boiling ethanol in a Soxhlet extractor for $18 \mathrm{~h}$, dried at $100^{\circ}$ for $3 \mathrm{~h}$ and weighed. The dry fat-free bones were ashed at $800^{\circ}$ to constant weight.

The mandibular incisors were removed from each animal, extracted with ethanol, dried, weighed and ashed as for the bones.

Histological examinations. The femurs and maxillary incisors were dissected, decalcified, sectioned and stained as described by Ferguson \& Hartles (1963, 1964).

\section{RESULTS}

The terminal body-weights and findings relating to serum and bones are given in Table 1 . The results for the incisor teeth are shown in Table 2.

The results were subjected to an analysis of variance in which the total treatment variation was divided into that due to treatments, that due to the blocks and the residual or error variation. The treatment variation was then subdivided into that due to vitamin $\mathrm{D}$, that due to the alteration in dietary $\mathrm{Ca}$ and $\mathrm{P}$, and that due to the interaction of these two factors.

The following comparisons were made:

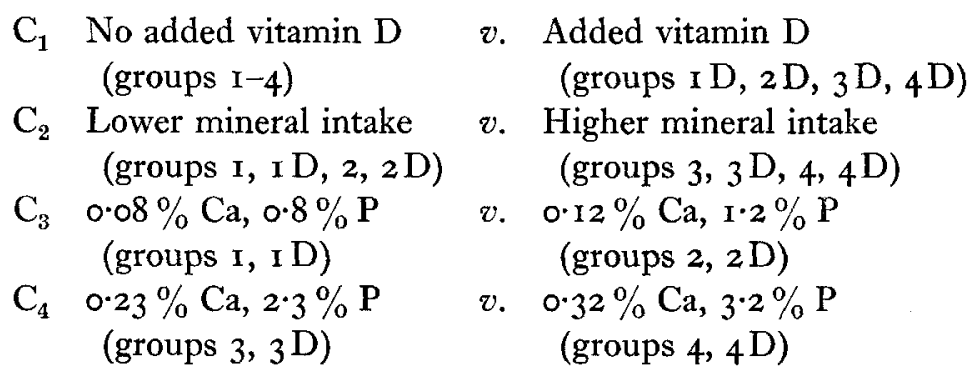

Consequentially the following interactions were determined: $\mathrm{C}_{1} v \cdot \mathrm{C}_{2} ; \mathrm{C}_{1}$ v. $\mathrm{C}_{3}$; $\mathrm{C}_{1}$ v. $\mathrm{C}_{4}$. The significance levels for all comparisons are shown in Table 3 .

\section{Histological examination}

Femurs. The width of the epiphyseal cartilage was within normal limits in all the groups. In group I the shaft of the bone appeared porotic, osteoid seams were visible, and the shaft was thinner than normal. The appearance of group i D femurs 

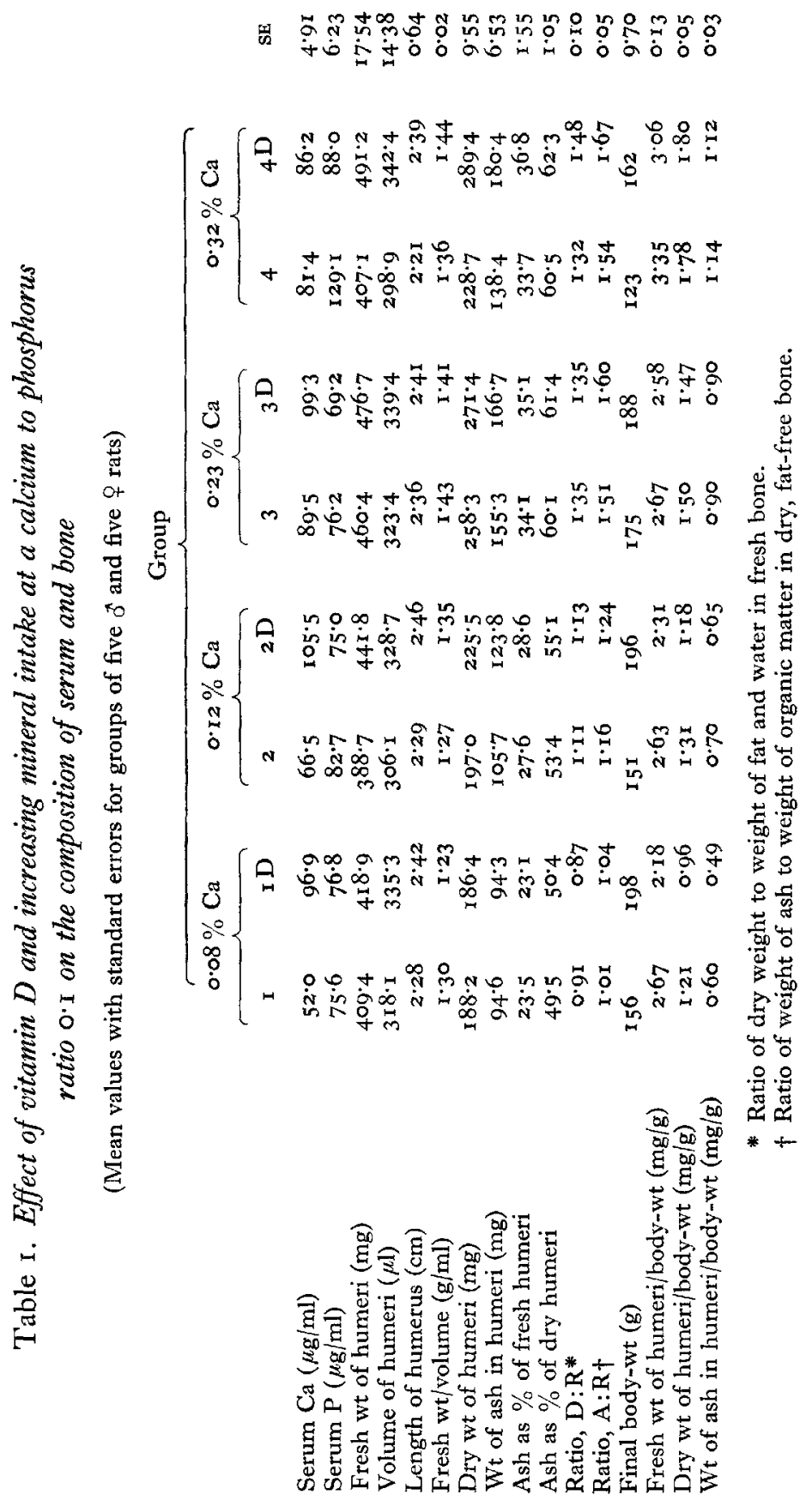


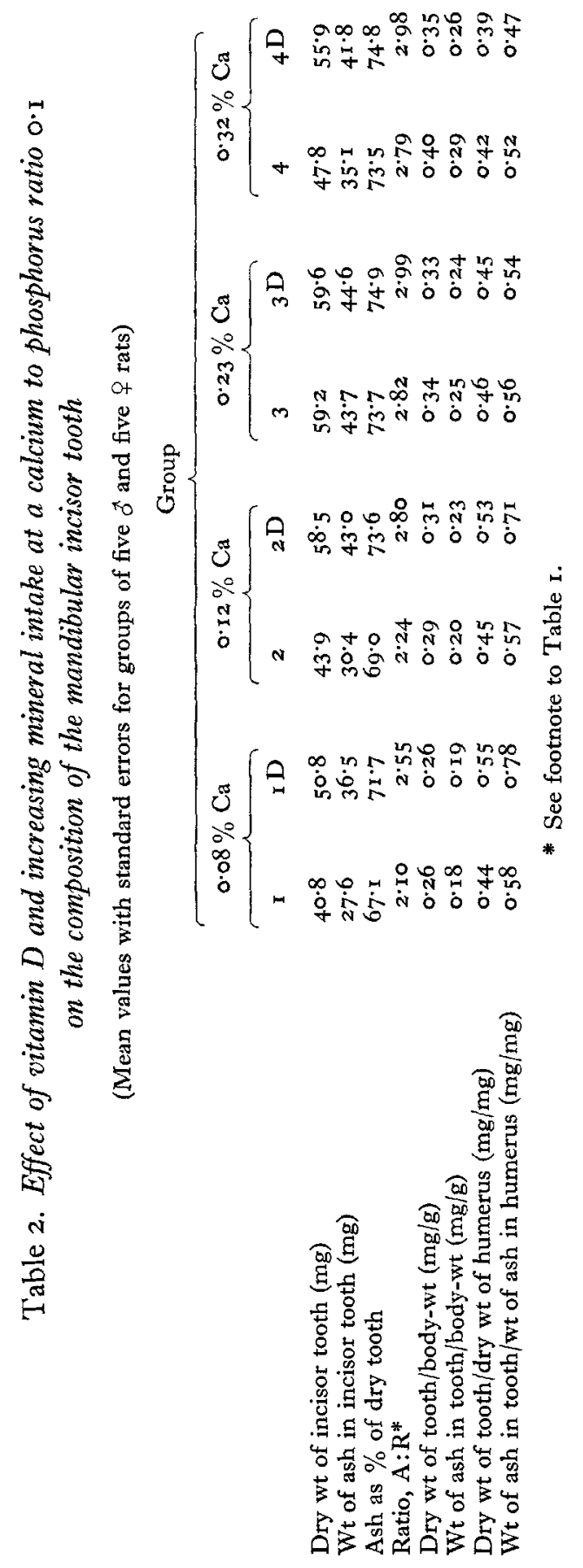


was less porotic but the metaphyseal trabeculae and shaft were even thinner and osteoid tissue was rarely observed (Pl. I $a, b$ ). In group 2 animals there were patches of osteoid in the shaft of the femur. There were no demonstrable departures from normal appearance in any other group.

Incisor teeth. In contrast to the bones there were some changes in histological appearance in the teeth from all groups.

Group $\mathrm{I}$ : in the apical region, the pre-dentine, which is normally less than onesixth as wide as the dentine, was wider than the dentine and its border was irregular. The incisal pre-dentine was also very wide, and there were many unfused calcospherites in the dentine (P1. 2c).

Table 3. Significance levels $(P)$ for the effects on bones and teeth of rats of vitamin $D$, increased dietary mineral content and their interaction $(I)$

\begin{tabular}{|c|c|c|c|c|c|c|c|}
\hline & $\begin{array}{c}\text { Vitamin } \\
\text { D }\end{array}$ & $\begin{array}{l}\text { Groups I } \\
\text { and } 2 \\
\text { v. } 3 \text { and } 4\end{array}$ & I & $\begin{array}{c}\text { Groups I } \\
v . \\
\text { groups } 2\end{array}$ & $\mathbf{I}$ & $\begin{array}{c}\text { Groups } 3 \\
v . \\
\text { groups } 4\end{array}$ & I \\
\hline Serum Ca & 0.001 & 0.001 & $0.00 \mathrm{r}$ & 0.01 & NS & 0.01 & NS \\
\hline Serum $\mathbf{P}$ & 0.01 & 0.001 & 0.025 & NS & NS & 0.001 & $0.0 \mathrm{r}$ \\
\hline Fresh wt of humeri & 0.001 & 0.001 & NS & NS & NS & NS & 0.01 \\
\hline Volume of humeri & 0.001 & NS & NS & NS & NS & NS & NS \\
\hline Length of humerus & 0.01 & NS & NS & NS & NS & NS & NS \\
\hline Fresh wt/volume & NS & 0.001 & NS & 0.025 & 0.001 & NS & $0.0 \mathrm{r}$ \\
\hline Dry wt of humeri & 0.001 & 0.001 & 0.05 & 0.01 & 0.05 & NS & 0.01 \\
\hline Wt of ash in humeri & 0.001 & 0.001 & 0.025 & $0.00 \mathrm{I}$ & $\mathrm{NS}$ & NS & 0.01 \\
\hline Ash as $\%$ of fresh humeri & 0.025 & 0.001 & NS & $0.00 \mathrm{r}$ & NS & NS & NS \\
\hline Ash as $\%$ of dry humeri & 0.01 & $0.00 I$ & NS & 0.001 & NS & NS & NS \\
\hline Ratio, D: R* & NS & 0.001 & NS & 0.001 & NS & NS & NS \\
\hline Ratio, A: R* & 0.01 & 0.001 & NS & 0.001 & NS & NS & NS \\
\hline Final body-wt & 0.001 & 0.01 & NS & NS & NS & 0.001 & 0.05 \\
\hline Fresh wt of humeri/body-wt & 0.001 & 0.001 & 0.05 & NS & NS & 0.001 & $\mathrm{NS}$ \\
\hline Dry wt of humeri/body-wt & 0.01 & 0.001 & 0.01 & 0.01 & NS & 0.001 & NS \\
\hline Wt of ash in humeri/body-wt & 0.025 & $0.00 \mathrm{r}$ & 0.05 & 0.001 & NS & 0.001 & NS \\
\hline Dry wt of incisor tooth & 0.001 & 0.001 & $0.00 \mathrm{I}$ & 0.001 & NS & 0.001 & 0.025 \\
\hline Wt of ash in incisor tooth & 0.001 & 0.001 & 0.001 & $0.00 \mathrm{I}$ & NS & 0.001 & 0.025 \\
\hline Ash as $\%$ of dry tooth & 0.001 & 0.001 & 0.001 & 0.01 & NS & NS & $\mathrm{NS}$ \\
\hline Ratio A:R & 0.001 & 0.001 & 0.001 & 0.01 & NS & NS & NS \\
\hline Dry wt of tooth/body-wt & 0.025 & 0.001 & 0.001 & 0.001 & NS & 0.001 & 0.05 \\
\hline Wt of ash in tooth/body-wt & NS & 0.001 & 0.001 & 0.001 & NS & 0.001 & NS \\
\hline $\begin{array}{l}\text { Dry wt of tooth/dry wt of } \\
\text { humerus }\end{array}$ & 0.01 & 0.001 & 0.001 & NS & NS & 0.01 & NS \\
\hline Wt of ash in tooth/wt of ash & $0.00 \mathrm{r}$ & 0.001 & 0.001 & NS & NS & 0.01 & NS \\
\hline
\end{tabular}

NS, not significant. * See footnotes to Table I.

Group I D: the apical pre-dentine was almost as wide as the dentine, but in the incisal region the pre-dentine and dentine were of normal width but there were signs of incomplete fusion of calcospherites (P1. $2 d$ ).

Group 2: pre-dentine in the apical region was again wider than the dentine which contained unfused calcospherites. The incisal dentine was similar to that in group $\mathrm{I}$.

Group 2 D: apically the pre-dentine was wider than normal and its margin was irregular. The incisal dentine and pre-dentine appeared normal.

Group 3: the apical pre-dentine was wider than normal and the junction was 
slightly irregular. The dentine exhibited incremental banding. Incisally the dentine was normal in appearance.

Group $3 \mathrm{D}$ : apically the pre-dentine was wider than normal, incisally both dentine and pre-dentine appeared normal.

Group 4: the apical pre-dentine was slightly wider than normal, but the incisal portion of the tooth was normal in appearance.

Group ${ }_{4} \mathrm{D}$ : the tooth appeared normal except for a slightly banded appearance in the dentine.

Alveolar bone. In groups $\mathrm{I}, \mathrm{I} D, 2$ and $2 \mathrm{D}$ there was cavitation of the alveolar bone; in the absence of vitamin D (groups I and 2) small amounts of osteoid could be demonstrated, in the presence of the vitamin there was no demonstrable osteoid. In all other groups the alveolar bone appeared normal.

\section{DISCUSSION}

Although many studies have been carried out in the rat involving changes in the absolute and relative amounts of $\mathrm{Ca}$ and $\mathrm{P}$ in the diet, none has been done where the ratio of $\mathrm{Ca}$ to $\mathrm{P}$ was $\mathrm{O}^{\circ} \mathrm{I}$ and the range of $\mathrm{Ca}$ varied from the grossly inadequate to the near optimal in the presence and absence of vitamin D.

Bethke, Kick \& Wilder (1932) studied young rats maintained on diets containing $0.35,0.52$ and $0.63 \% \mathrm{Ca}$, with a $\mathrm{Ca}$ to $\mathrm{P}$ ratio of 0.25 . In the absence of vitamin $\mathrm{D}$ both serum $\mathrm{Ca}$ concentration and the ash content of the femurs were below normal in all animals. When vitamin $\mathrm{D}$ was added to the diets the serum $\mathrm{Ca}$ and bone ash increased in each group but the increase was slightly more in the rats receiving the lowest dietary Ca. However, the lowest level of $\mathrm{Ca}(0.35 \%)$ was greater than our highest $(0.32 \% \mathrm{Ca})$ and it is likely that there were no significant differences between the effects of the three levels of dietary $\mathrm{Ca}$. In the absence of vitamin $\mathrm{D}$ all diets were inadequate for proper bone formation; when vitamin $\mathrm{D}$ was added all were improved. In the present study the range of dietary $\mathrm{Ca}$ content was such as to enable the effect of increased mineral intake to be distinguished from that of vitamin $\mathrm{D}$.

\section{Growth of animals}

The addition of vitamin $\mathrm{D}$ to the die had a highly significant effect on final bodyweight at all levels of dietary $\mathrm{Ca}$ and $\mathrm{P}$. At the highest level of mineral intake and in the absence of vitamin $\mathrm{D}$ the final body-weight was significantly lower than in the other groups. Thus the presence of an adequate supply of vitamin D minimizes the deleterious effect on growth of a gross imbalance between dietary $\mathrm{Ca}$ and $\mathrm{P}$. These results reaffirm those of Bicknell \& Prescott (1946) that vitamin D promotes a general stimulation of growth.

\section{Serum $C a$ and $P$}

The results of these experiments where the $\mathrm{Ca}$ to $\mathrm{P}$ ratio was excessively low underline the function of vitamin $\mathrm{D}$ in regulating serum $\mathrm{Ca}$ and $\mathrm{P}$ concentration in the young rat, a view formulated in general terms by Kramer \& Howland (1932). The effect of the vitamin in raising the serum $\mathrm{Ca}$ concentration was highly significant and 
was quantitatively greater at the lower levels of dietary $\mathrm{Ca}$. The effect of the vitamin on the lowering of the serum $P$ concentration was significant and was quantitatively greater at the highest level of dietary $\mathrm{P}$. When the results are presented graphically (Fig. I) they provide a striking illustration of the reciprocal nature of the effect of vitamin $\mathrm{D}$ in the young rat when there is a dietary deficiency of $\mathrm{Ca}$ and when there is a superabundance of $P$.

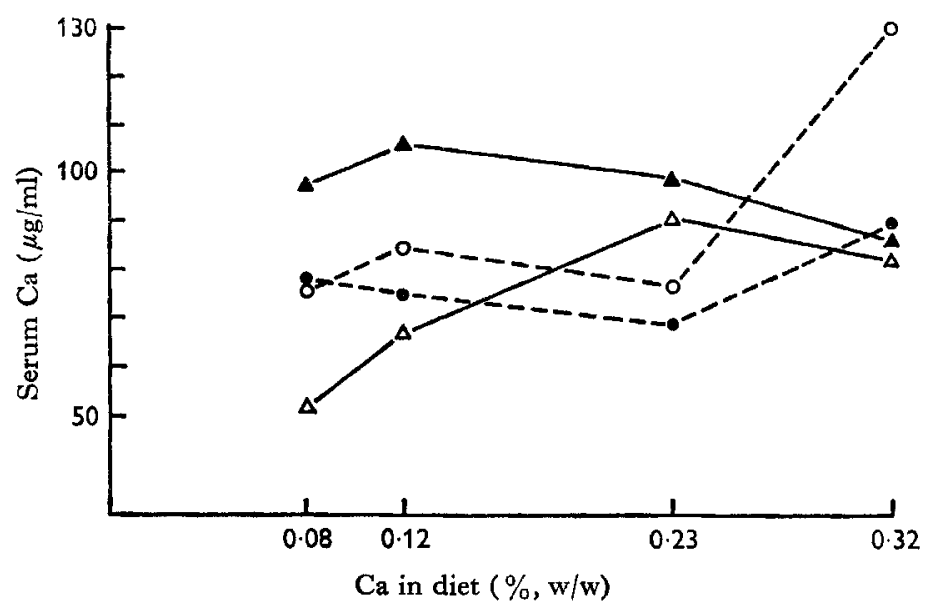

Fig. I. Effect of vitamin $D$ and increasing dietary mineral content at a calcium to phosphorus ratio of 0.1 on serum $C a$ and $P$ in rats. $\triangle-\triangle$, serum $C$ a without vitamin $D ; \Delta-\Delta$, serum $C a$ with vitamin $\mathbf{D} ; 0-0$, serum $\mathbf{P}$ without vitamin $\mathrm{D} ; \mathbf{0}-\mathbf{O}$, serum $\mathbf{P}$ with vitamin $\mathbf{D}$.

\section{Bones and incisor teeth}

When the results for all the groups without vitamin $D$ are compared with those for all the groups with it several significant differences can be shown. In the presence of the vitamin, the length, volume, fresh weight, dry weight, weight of ash, percentage of ash and ratio of ash to organic matter in the dry fat-free bone (A:R), of the humeri were all significantly greater than in its absence. On the other hand, the ratio of dry matter to water plus fat in the fresh bone (D:R) and the ratio of fresh weight to volume were not significantly changed by the addition of vitamin $\mathrm{D}$ to the diet. These results emphasize that vitamin $D$ has an effect on the growth pattern of the bone as well as on mineralization. Even so the ratios of the mass of bone formed to the body-weight and of the weight of bone ash to body-weight were significantly lower in the presence of vitamin $\mathrm{D}$, indicating that in the circumstances of this experiment the vitamin has a relatively greater effect on body-weight than on bone weight. This finding is in accord with that of Gaster, Havivi \& Guggenheim (1967) who showed that the addition of vitamin $\mathrm{D}$ to a low-Ca diet resulted in a gain in body-weight which was proportionately greater than the increase in bone weight.

Increasing the dietary mineral content produced more variable results. The fresh weights of the humeri were significantly greater in the combined groups $3,3 \mathrm{D}, 4$ and ${ }_{4} \mathrm{D}$ than in the combined groups $\mathrm{I}, \mathrm{ID}, 2$ and $2 \mathrm{D}$, but there were no significant differences between the groups with the two lower intakes of mineral or between the groups with the two higher levels. Nor was there any significant effect of varying 


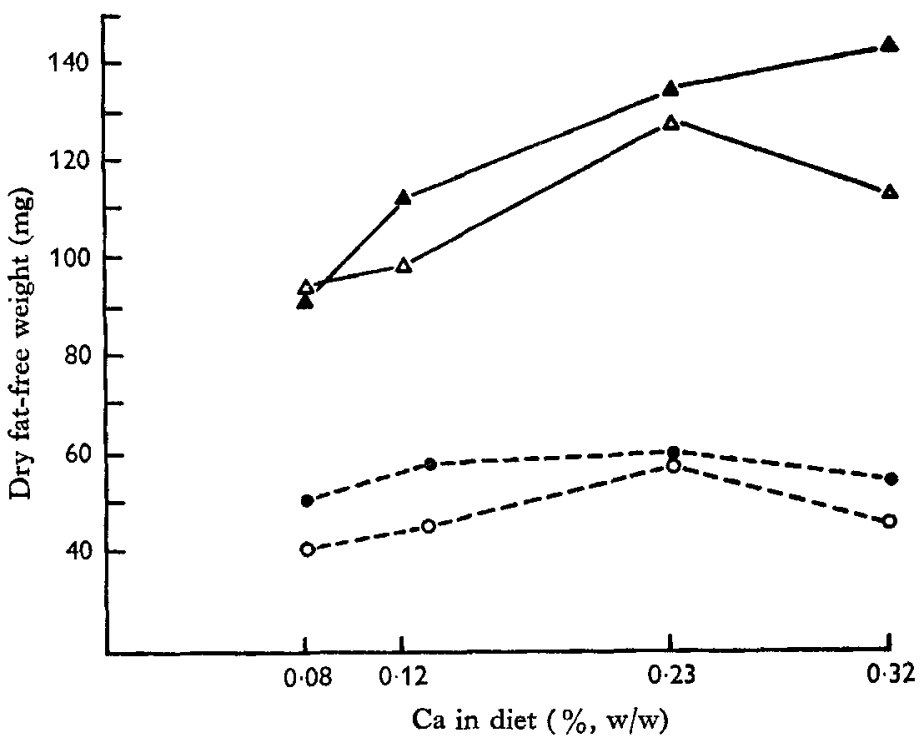

Fig. 2. Effect of vitamin $\mathrm{D}$ and increasing dietary mineral content at a calcium to phosphorus ratio of $O \cdot I$ on the dry fat-free weight of humerus and lower incisor tooth of rats. $\triangle-\triangle$, bone weight without vitamin $\mathrm{D} ; \boldsymbol{\Delta}-\mathbf{\Delta}$, bone weight with vitamin $\mathrm{D} ; \mathrm{O}-\mathrm{O}$, tooth weight without vitamin $D$; $-O$, tooth weight with vitamin $D$.

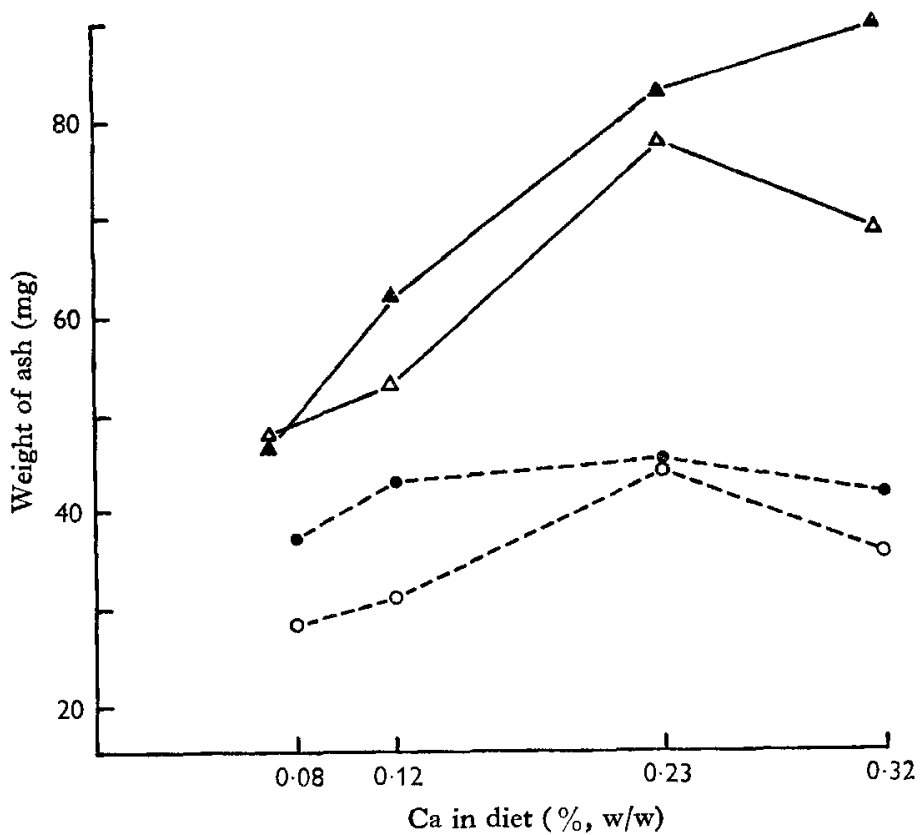

Fig. 3. Effect of vitamin $D$ and increasing dietary mineral content at a calcium to phosphorus ratio of $0^{\circ} \mathrm{I}$ on the weight of ash in the humerus and lower incisor tooth of rats. $\triangle-\triangle$, bone ash weight without vitamin $\mathrm{D} ; \boldsymbol{\Delta}-\boldsymbol{\Delta}$, bone ash weight with vitamin $\mathrm{D} ; 0-\mathrm{O}$, tooth ash weight without vitamin $D ; 0-0$, tooth ash weight with vitamin $D$. 
mineral intake on bone volume or bone length. The weight of ash, percentage of ash, $A: R$ and $D: R$ ratios were all significantly raised as mineral intake increased except at the highest level of dietary mineral. The ratios of fresh weight, dry weight and weight of ash in the humeri to body-weight were significantly raised as mineral intake increased, thus demonstrating that a rising mineral intake has a greater effect on bone mass and the amount of mineral deposited in bone than on general body-weight. This is in direct contrast to the effect of vitamin D.

The presence of vitamin $D$ in the diet significantly increased the dry weight, weight of ash, percentage of ash and $A: R$ ratio of the incisor tooth.

If the results for dry weight and weight of ash for both bones and teeth are presented graphically (Figs. 2, 3) several interesting points can be easily seen. Quantitatively the greatest effect of vitamin D on the teeth was at the lower levels of mineral intake when the dietary $\mathrm{Ca}$ was low but the $\mathrm{P}$ more than adequate. This effect is also seen in the tooth sections (Pl. 2c, d). Conversely, the greatest effect of the vitamin on the bone was at the highest level of mineral intake when the dietary $\mathrm{Ca}$ was approaching adequacy $(0.32 \%)$ and the $P$ was very high.

In addition, when the $\mathrm{Ca}$ intake was low, the effect of vitamin $\mathrm{D}$ was greater on the teeth than on the bones, whereas when the $P$ intake was very high the effect of the vitamin was greater on the bones.

Thus, when there was a severe lack of $\mathrm{Ca}$ and of vitamin $\mathrm{D}$, serum Ca concentration was low; in these circumstances the addition of vitamin $\mathrm{D}$ to the diet raised serum $\mathrm{Ca}$ concentration and increased the absolute amount of mineral deposited in the incisor tooth but did not, at this low level of dietary $\mathrm{Ca}$, affect the mass of bone formed or its ash content. On the other hand, when the dietary $\mathrm{Ca}$ was increased, in the continued absence of vitamin $\mathrm{D}$ (group 4 ) the concomitant increase in dietary $\mathrm{P}$ caused a very high serum $P$ concentration; in these conditions the provision of vitamin $D$ resulted in a lowering of serum $P$ concentration and a much greater increase in mineral deposited in the bone than in the tooth. Gaunt \& Irving (I940) and Irving (1957) have put forward the idea that teeth and bone react differently to deficiencies of $\mathrm{Ca}$ and $\mathrm{P}$. They showed that, when the intake of both $\mathrm{Ca}$ and $\mathrm{P}$ is inadequate, the calcification of the teeth is more disturbed by diets with a $\mathrm{Ca}$ to $\mathrm{P}$ ratio of 0.5 than by diets with a ratio $\mathrm{I} \cdot \mathrm{O}$ or $4^{\circ} \mathrm{O}$. Conversely, they showed that bone formation is more disturbed by diet with a high $\mathrm{Ca}$ to $\mathrm{P}$ ratio.

Ferguson \& Hartles (1964) showed that, when the diet contained $0.026 \% \mathrm{Ca}$, $0.06 \% \mathrm{P}$ and no added vitamin $\mathrm{D}$, the incisor teeth were severely affected, as were the bones. The addition of vitamin $\mathrm{D}$ to this diet resulted in a dramatic improvement in the mass of tooth formed and its mineralization, but there was no similar quantitative effect on bone. These results suggest that there may be fundamental differences in the manner in which the bones and teeth acquire mineral. Reference to Figs. 2 and 3 provides unequivocal confirmation that when the diet is low in $\mathrm{Ca}$ but adequate in $\mathrm{P}$ vitamin $D$ exerts a greater improvement in the tooth than in the bone.

As the mineral intake was raised (groups 2 and $2 \mathrm{D}$ ) the effect of the vitamin on bone and tooth increased, but declined in groups 3 and $3 \mathrm{D}$, increasing again in groups 4 and ${ }_{4} \mathrm{D}$. 
Histological examination of the bones in groups I and I D showed them to be porotic but osteoid seams were demonstrable only in the absence of vitamin D. A frankly rachitic condition with wide epiphyseal cartilage was never seen. When the mineral intake was raised in groups 2 and $2 \mathrm{D}$ the porosis was no longer apparent, but again in the absence of the vitamin some osteoid patches were present. With further increase in dietary mineral at the same low $\mathrm{Ca}$ to $\mathrm{P}$ ratio, the histological appearance of the bone was indistinguishable from normal.

Thus in the circumstances of this experiment it can be concluded that the major effect of vitamin $\mathrm{D}$ is on the quantity of bone formed, although it does have a small but significant effect in raising the percentage ash content of the bone. Increasing the mineral intake affects both the quantity and quality of the bone formed, except that at the highest level of dietary mineral the quantity of bone is reduced in the absence of vitamin $D$. The significant interaction between the effects of the vitamin and increased mineral intake in groups 3 and $3 \mathrm{D}$ and 4 and ${ }_{4} \mathrm{D}$ indicates that the effect of the vitamin is more than additive and is actively involved in promoting the deposition of an increased quantity of mineral.

Irving (1957) concluded from his survey of the literature that in man high phosphate intakes are without effect on $\mathrm{Ca}$ metabolism. In the rat this would not seem to be the case, for in the absence of vitamin $\mathrm{D}$ there is a reduction in bone mass in the animals of group $4(0.32 \% \mathrm{Ca})$ compared with those in group $3(0.23 \% \mathrm{Ca})$.

The reaction of the teeth to the low dietary $\mathrm{Ca}$ to $\mathrm{P}$ ratio was different from that of the bones. In every group a disturbance of histological appearance was observed, but at each level of dietary mineral the presence of vitamin D ameliorated the condition until at the highest level of mineral intake the appearance of the tooth was almost normal.

It is interesting to examine the ratios of tooth weight and ash to bone weight and ash in all the groups. Comparing the two lower with the two higher levels of dietary mineral, there is a significant fall in the ratios and a significant interaction with vitamin $\mathrm{D}$ (Tables $\mathrm{I}-3$ ). Thus, in general, increasing the mineral intake at a $\mathrm{Ca}$ to $\mathrm{P}$ ratio of $\mathrm{o} \cdot \mathrm{I}$ results in a greater increase in dry bone weight and ash than dry tooth weight and ash. However, vitamin $\mathrm{D}$ had an effect of raising the ratio of tooth weight to bone, but inspection of Table 2 shows that this effect was confined to groups I, I D, 2 and $2 \mathrm{D}$. Thus at the lower levels of mineral intake the vitamin encourages tooth formation rather than bone formation, whereas at the higher levels of dietary mineral this effect is no longer apparent.

The authors wish to thank Mr R. P. Williams for care and maintenance of the animals, Miss Greta Rixom for technical assistance and $\mathrm{Mr}$ J. S. Bailie for the photomicrography. 


\section{REFERENCES}

Bethke, R. M., Kick, C. H. \& Wilder, W. (1932). F. biol. Chem. 98, 389.

Bicknell, F. \& Prescott, F. (1946). The Vitamins in Medicine, and ed., p. 645. London: William Heinemann Medical Books Limited.

Ferguson, H. W. \& Hartles, R. L. (1963). Archs oral Biol. 8, 407.

Ferguson, H. W. \& Hartles, R. L. (1964). Archs oral Biol. 9, 447.

Gaster, D., Havivi, E. \& Guggenheim, K. (I967). Br. F. Nutr. 21, 413.

Gaunt, W. E. \& Irving, J. T. (1940). F. Physiol., Lond. 99, I8.

Harrand, R. B., Green, R. M. \& Hartles, R. L. (I 966). Br. F. Nutr. 20, 55.

Hartles, R. L. \& Leaver, A. G. (196r). Archs oral Biol. 5, 38.

Hartles, R. L., Leaver, A. G, \& Triffitt, J. T. (1963). Archs oral Biol. 8, 657.

Irving, J. T. (1957). Calcium Metabolism. London: Methuen.

Kramer, B. \& Howland, J. (I932). F. Nutr. 5, 39.

\section{EXPLANATION OF PLATES}

Plates I AND 2

Effect of vitamin $\mathrm{D}$ on bone and tooth of rats given a diet containing $0.08 \%$ calcium and $0.8 \%$ phosphorus. Haematoxylin and eosin.

$$
\text { Plate I }
$$

(a) and $(b)$. Longitudinal section through the shaft of decalcified femur of an animal (a) from group I (no vitamin D) showing porotic appearance of bone with some osteoid seams visible, and (b) from group I $D$ (with vitamin $D$ ) showing a thinner shaft with less porosis in the endosteal bone and an absence of demonstrable osteoid.

\section{Plate 2}

(c) and (d). Longitudinal section from the middle region of a decalcified incisor tooth of an animal (c) from group I (no vitamin D) showing wide irregular pre-dentine and unfused calcospherites, and $(d)$ from group I D (with vitamin D) showing an almost normal width of pre-dentine and an increased coalescence of calcospherites. 

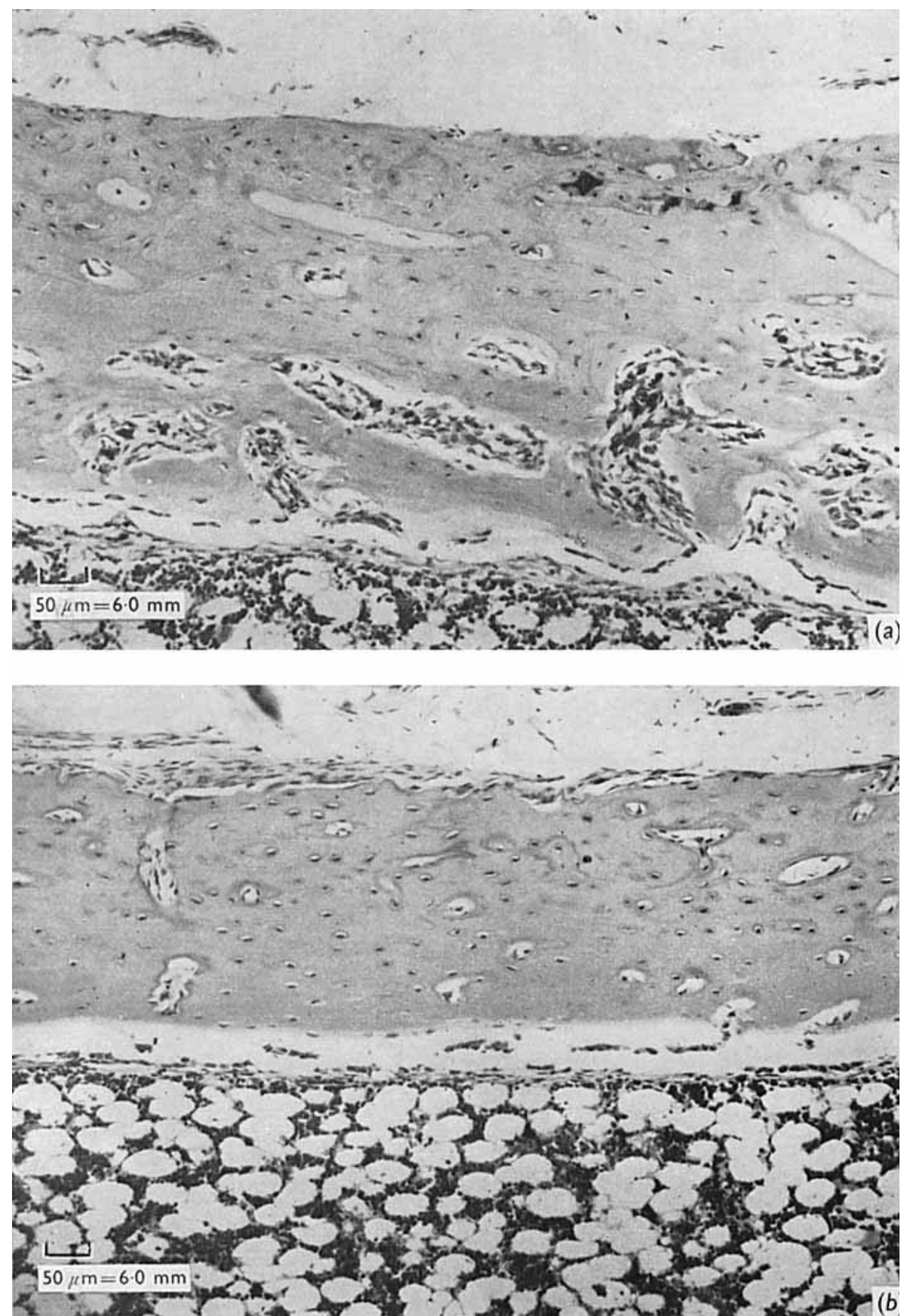

R. B. HARRAND AND R. L. HARTLES

(Facing p. 56) 

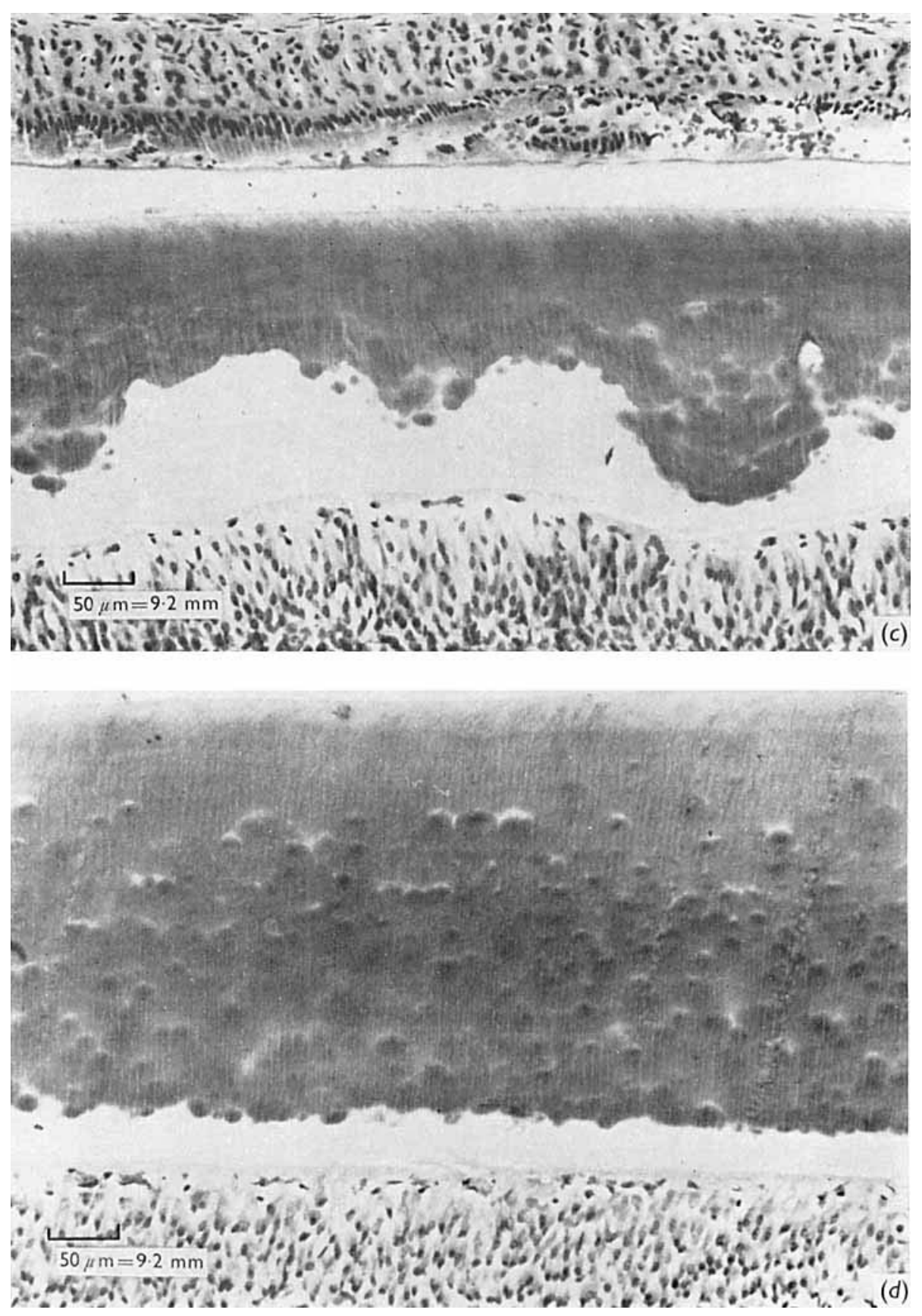

R. B. HARRAND AND R. L. HARTLES 